\title{
Personality, depression, and premorbid lifestyle in twin pairs discordant for Parkinson's disease
}

\author{
Ilse Heberlein, Hans-Peter Ludin, Joachim Scholz, Peter Vieregge
}

\begin{abstract}
Present personality traits (Freiburg personality inventory, FPI-R), depression (von Zerssen's depression scale), and self assessed state of health were evaluated in 15 twin pairs (six monozygotic and nine dizygotic; mean age 62.5 years) discordant for idiopathic Parkinson's disease and in 17 unrelated healthy control subjects. The twins had additional questionnaire based interviews on premorbid lifestyle.

For disability, twins with Parkinson's disease scored lower on FPI-R than controls in "achievement orientation" and "extraversion", higher in "inhibitedness", "somatic complaints", and "emotionality". They scored higher for depression and for state of health than unaffected twins and controls. For zygosity, monozygotic twins scored lower than dizygotic twins in "achievement orientation", "aggressiveness", and "strain". Monozygotic twins had less "achievement orientation" and "extraversion" and more "somatic complaints" than controls. Monozygotic twins had a lower within pair difference than dizygotic twins in "social orientation". During premorbid times the affected twin with later Parkinson's disease was estimated to have been "less often the leader" in the twin pair.

Although small in sample size, this twin study indicates a genetic impact for some personality features beyond the Parkinson's disease motor syndrome.
\end{abstract}

(F Neurol Neurosurg Psychiatry 1998;64:262-266)

Keywords: Parkinson's disease; twin research; genetics; personality traits

Neurological Clinic Kantonsspital St Gallen, Switzerland H-P Ludin

Correspondence to: Dr Peter Vieregge, Department of Neurology, Medical University of Lubeck, Ratzeburger Allee 160, D-23538 Lubeck, Germany. Telephone 0049 451500 2928; fax 004945 5002489 .

Received 27 July 1996 and in revised form 29 July 1997 Accepted 31 July 1997 early in "premorbid" Parkinson's disease. Whether patients with later Parkinson's disease are less talkative and flexible, more generous, even tempered, cautious, overcontrolled, and depressed before onset of motor symptoms, ${ }^{89}$ is a matter of a continuing debate. ${ }^{1011}$ Overall, such personality and mood changes in patients with Parkinson's disease have been at least partially attributed to a "subclinical" damage of the mesocortical system that originates from the dopaminergic cell bodies of the ventral segmental area. ${ }^{12}$ This system is known to be already afflicted at the time when the Parkinson's disease motor syndrome emerges, ${ }^{14}$ but it was not investigated in the above mentioned PET studies. ${ }^{67}$ Converging with the concept of a premotor Parkinson's disease are anecdotal reports - fraught with inherent recall bias - in which the subsequently afflicted twin of a discordant monozygotic pair had been rated to be different in his personality, yet during the premorbid period childhood life stages were shared by both twins. ${ }^{15}$

Pursuing the idea of a non-motor Parkinson's disease syndrome the present study compares current personality traits and mood in twin pairs discordant for Parkinson's disease. It uses a group of healthy age and sex matched subjects as controls. By application of questionnaires standardised for a healthy population of whom the native language was German it was expected that the twin approach would help to clarify a possible genetic contribution to the non-motor features of Parkinson's disease. Additionally, premorbid lifestyles were also studied in the twins by a questionnaire based semistructured interview.

\section{Methods}

From Germany and Switzerland 15 German speaking non-demented twin pairs discordant for Parkinson's disease were included in the study. Sampling and clinical evaluation methods, diagnostic criteria for Parkinson's disease, and zygosity determination in this twin sample have been published earlier. ${ }^{4}$ All discordant twin pairs who had participated in the earlier PET investigation ${ }^{7}$ also took part in this evaluation. Unaffected co-twins had to be free of relevant general medical, neurological, and psychiatric disability. None of them took any drug acting on the CNS. Controls were healthy medical personnel and senior citizens living 
independently in the community. For inclusion, control persons and their first degree relatives had to be free of neurological disease. Further exclusion criteria for the controls were history or signs of any CNS or psychiatric disease, alcohol, substance, or drug misuse, history of exposure to CNS relevant toxins, or any disabling general medical condition. During the semistructured check up interview for study participation potentially stressful life events were also asked for. All subjects took part in the study after having given their informed oral consent.

Personality was assessed with the Freiburg personality inventory (FPI-R). ${ }^{16}$ In this test 10 traits and two dimensions of personality ("extraversion/introversion"; "emotional stability/instability") are described from answers to 138 questions. Those with emotional instability are considered to be more anxious, sensitive, and labile. Raw scores of FPI-R were transformed into age and sex corrected scores. Stanine scores normalised for German adults. Depressive mood was assessed by the "depression scale" (D-S). ${ }^{17}$ Finally, a questionnaire about self assessed state of health-the "Befindlichkeits-Skala" (Bf-S $)^{18}$ — was applied. This scale was originally created to assess cyclothymic subjects in their subjective wellbeing between mood fluctuations. Raw scores of D-S and Bf-S were not transformed to Stanine scores, as there are no normative data for German probands above 64 years of age. Cognitive testing was carried out on the motor affected twins with the mini mental state examination, ${ }^{19}$ and only subjects with a score above 23 were included in this study. Unaffected co-twins and and control persons were clinically assessed, but had no formal testing of cognition. All participants filled out the questionnaires independent of each other in their respective homes or in a quiet room of the department, while one of the investigators was present. The twins were additionally interviewed by a questionnaire based semistructured interview for demographic characteristics during childhood and adolescence, premorbid lifestyle, and personality. Specifically, number of education years, job history, number of moves, and of years living at home were asked for.

Additionally, hobbies, number and characterisation of personal friendships, memberships, travelling, and consumer habits were studied. Study hypotheses were not disclosed to the participants. Except for travel expenses no subject was paid for participation.

Statistical analyses were performed using the PC version of the statistical package of the social sciences (SPSS-PC). Within each of the five subject groups (affected twins, unaffected twins, monozygotic twin group, dizygotic twin group, controls) the mean and SD were calculated for each continuous variable. Analysis of variance (ANOVA) was conducted on personality and mood variables using the nonparametric Kruskal-Wallis test. When the Kruskal-Wallis test was significant, post hoc comparisons were made with the TukeyKramer test. The Mann-Whitney $U$ test was applied to compare within pair differences between monozygotic and dizygotic twin pairs. Correlations among personality and mood variables were calculated using the Spearman correlation coefficient, in which $\mathrm{p}$ values $<0.01$ were considered significant. Mean values of linear indices in demographic and lifestyle variables were compared by Student's $t$ test. Ordinally dichotomised variables among them were tested for two sided significance levels $(\mathrm{p}<0.05)$ by Pearson's $\chi^{2}$ test.

\section{Results}

All of the eligible twin and control candidates agreed to participate. Six monozygotic twin pairs (four men, two women; mean age 58 (SD 17) years) were tested. Mean age at onset of affected monozygotic twins was 50 (SD 17) years, their disease duration was 8 (SD 50) years. Their mean motor score on the unified Parkinson's disease rating scale (UPDRS-III) ${ }^{20}$ was 33 (SD33) (range 20-47). Nine dizygotic twin pairs were tested (mean age 65 (SD 33) years), two of whom were same sex pairs. Mean age at onset of the dizygotic twins affected with Parkinson's disease (five men, four women) was 58 (SD 9) years; their disease duration was 6 (SD 4) years. Their mean UPDRS-III score was 19 (SD 22) (range 5-37). All affected twins had standard antiparkinsonian drug treatment. All twin pairs had been brought up together in their parents' homes until at least 18 years of age. None of the twin pairs was living together within the same household at the time of investigation. Mean age of the 17 control subjects (10 men, seven women) was 63 (SD 20). There was no difference between groups for stressful life events.

Table 1 shows the test results between twins with Parkinson's disease, unaffected twins, and controls. On FPI-R scales, twins with Parkinson's disease scored lower than controls in "achievement orientation" and "extraversion", higher in "inhibitedness", "somatic complaints" and "emotionality". No FPI-R item was different between twin groups. The control persons had more "health concern" on FPI-R than both twin groups. The twins with Parkinson's disease scored higher for depression on $\mathrm{D}-\mathrm{S}$ and for self assessed state of health on Bf-S than the unaffected twins and the controls. The scores for depressive mood and for state of health were not different between twins without motor asymptoms and controls. D-S scores correlated with "emotionality" on FPI-R in all three groups (affected twins: $r=0.77$; unaffected co-twins: $r=0.85$; controls: $r=0.70$ ), and with Bf-S scores in affected twins $(r=0.84)$ and unaffected co-twins $(r=0.76)$. Test findings in twins with Parkinson's disease did not correlate with age at onset of Parkinson's disease, duration of Parkinson's disease, or with UPDRS-III rating scores.

Table 2 shows zygosity status. On the FPI-R, monozygotic twins scored lower than dizygotic twins in "achievement orientation", "aggressiveness", and "strain". Compared with controls monozygotic twins had less "achievement orientation" and "extraversion" and more "somatic complaints". Dizygotic twins scored higher than controls in "inhibitedness", 
Table 1 Personality traits (FPI-R), depression (D-S), and state of health (Bf-S) in 15 twin pairs discordant for idiopathic Parkinson's disease and 17 healthy controls

\begin{tabular}{lllll}
\hline & Affected twins & $\begin{array}{l}\text { Unaffected } \\
\text { twins }\end{array}$ & Controls & p Value \\
\hline FPI-R: & $4.9(2.5)$ & $6.1(1.9)$ & $6.8(1.5)$ & 0.06 \\
$\quad$ Life satisfaction & $4.9(1.8)$ & $5.7(1.1)$ & $5.8(1.7)$ & 0.25 \\
Social orientation & $3.7(2.1)^{\star}$ & $4.9(2.1)$ & $5.8(1.5)$ & 0.02 \\
Achievement orientation & $6.2(2.2)^{\star}$ & $5.1(2.8)$ & $3.8(1.9)$ & 0.03 \\
Inhibitedness & $4.7(2.2)$ & $4.5(1.5)$ & $4.4(1.5)$ & 0.91 \\
Impulsiveness & $4.3(1.9)$ & $4.7(1.8)$ & $5.0(1.3)$ & 0.53 \\
Aggressiveness & $4.7(1.8)$ & $4.5(1.6)$ & $3.8(1.3)$ & 0.16 \\
Strain & $5.1(1.6)^{\star}$ & $4.3(1.9)$ & $3.0(1.5)$ & 0.004 \\
Somatic complaints & $4.2(1.6)^{\star}$ & $4.3(1.5)^{\star}$ & $6.1(1.5)$ & 0.003 \\
Health concern & $4.4(2.1)$ & $4.9(1.8)$ & $3.9(2.1)$ & 0.32 \\
Frankness & $3.5(1.9)^{\star}$ & $4.7(1.8)$ & $6.2(2.2)$ & 0.004 \\
Extraversion & $5.7(1.8)^{\star}$ & $4.7(1.7)$ & $3.4(1.5)$ & 0.005 \\
Emotionally & $14.7(8.2)^{\star} \dagger$ & $7.1(4.8)$ & $4.9(2.9)$ & 0.001 \\
D-S: & & & & \\
Depression & $24.7(15.2)^{\star} \dagger$ & $11.5(9.8)$ & $7.5(5.4)$ & 0.001 \\
Bf-S: & & & & \\
State of health & &
\end{tabular}

Values are means (SD).

* Significant differences between twins and controls.

† Significant differences between twin groups (Kruskal-Wallis ANOVA with post hoc Tukey-Kramer test).

Table 2 Personality traits (FPI-R), depression (D-S), and state of health (Bf-S) in six monozygotic $(M Z)$ and nine dizygotic twin pairs discordant for idiopathic Parkinson's disease and 17 healthy controls

\begin{tabular}{lllll}
\hline & $M Z(n=12)$ & $D Z(n=18)$ & Controls $(n=17)$ & p Value \\
\hline FPI-R: & $5.3(2.7)$ & $5.7(2.0)$ & $6.8(1.5)$ & 0.12 \\
$\quad$ Life satisfaction & $5.1(1.4)$ & $5.4(1.7)$ & $5.8(1.7)$ & 0.55 \\
$\quad$ Social orientation & $3.2(1.5)^{\star} \dagger$ & $5.1(2.1)$ & $5.8(1.5)$ & 0.003 \\
Achievement orientation & $5.3(2.6)$ & $5.8(2.6)^{\star}$ & $3.8(1.9)$ & 0.049 \\
Inhibitedness & $4.3(1.8)$ & $4.8(1.9)$ & $4.4(1.5)$ & 0.58 \\
Impulsiveness & $3.7(1.1) \dagger$ & $5.1(2.0)$ & $5.0(1.3)$ & 0.02 \\
Aggressiveness & $3.7(1.5) \dagger$ & $5.2(1.5)^{\star}$ & $3.8(1.3)$ & 0.005 \\
Strain & $5.1(1.8)^{\star}$ & $4.4(1.8)$ & $3.0(1.5)$ & 0.005 \\
Somatic complaints & $4.1(1.3)^{\star}$ & $4.4(1.7)^{\star}$ & $6.1(1.5)$ & 0.002 \\
Health concern & $3.8(1.8)$ & $5.2(1.9)^{\star}$ & $3.9(2.1)$ & 0.04 \\
Frankness & $3.6(2.0)^{\star}$ & $4.5(1.8)$ & $6.2(2.2)$ & 0.006 \\
Extraversion & $4.8(2.1)$ & $5.4(1.5)^{\star}$ & $3.4(1.5)$ & 0.007 \\
Emotionally & $11.2(9.5)$ & $10.8(6.4)^{\star}$ & $4.9(2.9)$ & 0.009 \\
D-S: & $17.3(18.1)$ & $19.1(11.4)^{\star}$ & $7.5(5.4)$ & 0.01 \\
Depression & & & & \\
Bf-S: & & &
\end{tabular}

Values are means (SD).

* Significant differences between twins and controls.

$\dagger$ Significant differences between twin groups (Kruskal-Wallis ANOVA with post hoc Tukey-Kramer test).

Table 3 Intrapair differences (Mann-Whitney $U$ test) of personality traits (FPI-R), depression (D-S), and state of health (Bf-S) in six monozygotic (MZ) and nine dizygotic (DZ) twin pairs discordant for idiopathic Parkinson's disease

\begin{tabular}{llll}
\hline & $M Z(n=6)$ & $D Z(n=9)$ & $p$ Value \\
\hline FPI-R: & $4.7(3.8)$ & $3.1(1.5)$ & 0.53 \\
$\quad$ Life satisfaction & $0.5(0.6)$ & $3.2(2.0)$ & 0.001 \\
Social orientation & $2.7(2.7)$ & $4.6(2.8)$ & 0.18 \\
Achievement orientation & $3.8(3.4)$ & $4.6(2.9)$ & 0.69 \\
Inhibitedness & $1.7(1.6)$ & $3.9(2.0)$ & 0.05 \\
Impulsiveness & $1.3(1.2)$ & $2.7(2.3)$ & 0.33 \\
Aggressiveness & $1.7(2.4)$ & $3.4(1.2)$ & 0.09 \\
Strain & $2.5(2.9)$ & $3.4(1.7)$ & 0.22 \\
Somatic complaints & $2.2(2.3)$ & $3.3(2.4)$ & 0.39 \\
Health concern & $2.0(2.0)$ & $2.4(2.1)$ & 0.69 \\
Frankness & $3.5(4.2)$ & $3.7(3.0)$ & 0.86 \\
Extraversion & $4.0(4.3)$ & $4.1(2.5)$ & 0.61 \\
Emotionally & $12.0(11.7)$ & $6.4(5.1)$ & 0.53 \\
D-S: & $24.5(20.7)$ & $8.0(9.7)$ & 0.11 \\
Depression & & & \\
Bf-S: & & & \\
State of health & & & \\
\hline
\end{tabular}

Raw values are means (SD). tionality" on FPI-R in monozygotic twins $(r=0.80)$ and with Bf-S scores in dizygotic twins $(r=0.70)$.

Table 3 delineates the within pair differences of test items between the monozygotic and dizygotic twins. The only significant result was for the FPI-R item "social orientation", in which monozygotic twins showed a lower within pair difference than the dizygotic twins, whereas the item "impulsiveness" just failed to reach significance. Among the 45 premorbid demographic and lifestyle variables from the questionnaire based interview none was significantly different between the twins with Parkinson's disease and the unaffected twins (data not shown). The item of nearest significance was that the later Parkinson's disease affected twin was estimated to have been "less often the leader" in the twin pair $(\mathrm{p}<0.06)$.

\section{Discussion}

Within pair differences (significant for the FPI-R item "social orientation", borderline significant for "impulsiveness") point to differences in personality between monozygotic twins and dizygotic twins discordant for motor Parkinson's disease. To judge this finding three methodological issues have to be considered. Firstly, in general and irrespective of Parkinson's disease, is the social environment of monozygotic twins more alike than that of dizygotic twins. ${ }^{21}$ This may create personality assessments that are more similar in monozygotic than in dizygotic pairs. A second issue is that earlier retrospective assessments of personality in twins with Parkinson's disease have focused exclusively on discordant monozygotic pairs. ${ }^{15}$ Apart from recall bias, this is prone to overestimate a possible genetic impact on personality in Parkinson's disease. To take into account this factor not only dizygotic twins but also a control group from the general population were included in our study. Remarkably, even with this approach our study tends to confirm the result derived from the monozygotic twin study mentioned. ${ }^{15}$ The twin with later Parkinson's disease has been "less often the leader" in the twin pair. A third methodological issue is the bias created by investigation of volunteering twin pairs, particularly those discordant for a given condition. $^{22}$ To adjust for volunteering we advertised for control persons, similarly as for twins, in newpapers and lay organisations. So, some personality items in the control group were skewed: According to German normative data, item values between 4 to 6 on the FPI-R variables are considered to be "normal". Our controls scored more than 6 on "life satisfaction" and "extraversion", and less than 4 on "inhibitedness", "strain", "somatic complaints", and "emotionality". This points to a more enterprising, sociable control sample with a health concern higher than both twin groups, but with on average less somatic complaints and more emotional stability. Hence, the twin results found from comparisons in the FPI-R items "inhibitedness", "strain", "somatic complaints", "emotionality", and "extraversion" should not be overinterpreted. 
In our study variables reflecting genetic factors should be predicted by twin group rather than by diagnosis. Taking the group comparisons (tables 1 and 2) and the pecularities of the control group into account, the most conspicuous FPI-R findings in the monozygotic twins are the item value reductions in "achievement orientation" and "aggressiveness". These personality items coincide with the pattern derived from the already mentioned within pair analysis between monozygotic twins and dizygotic twins and fit earlier descriptions of a so-called Parkinsonian personality. ${ }^{89}$ In a study using the tridimensional personality questionnaire (TPQ) of Cloninger et $a l^{23}$ patients with Parkinson's disease scored lower in the dimension of "novelty seeking", but were not abnormal in other aspects of temperament. ${ }^{13}$ Dopamine is hypothesised to be the major neuromodulator of "novelty seeking". ${ }^{23}$ Thus dopamine deficiency may be one explanation of reduced "novelty seeking" in patients with Parkinson's disease and also for the personality findings in our monozygotic group.

Our investigation suggests but cannot prove that some personality features in motor asymptomatic twins are genetically bound. The same cautionary view applies to the inherent conclusion that these personality features could be the expression of a non-motor syndrome in at least some types of Parkinson's disease-for example, those with a strong genetic influence. In the general population, polymorphisms of exon sequence variants of the $\mathrm{D} 4$ dopamine receptor gene may account for about $10 \%$ of the genetic variation in the trait "novelty seeking". ${ }^{24}{ }^{25}$ Whether and how polymorphisms in this gene relate to "novelty seeking" in populations with distinct psychopathology-for example, also to patients with Parkinson's disease-remains to be seen.

The twins with Parkinson's disease are more depressed and give a lower self assessed state of health than both the healthy co-twins and the controls. Recent studies point to the role of depressive mood in personality assessment of disabled people. Differences in personality traits are no longer exclusively found in patients with Parkinson's disease when they are compared with patients with other chronic disabling illnesses. ${ }^{2627}$ As depression is a concomitant feature in several chronic conditions, ${ }^{28}$ disease burden is one explanation for our finding of depression in the twins with Parkinson's disease. It should be added that there were no group differences in stressful life events in our sample. On the other hand, monozygotic and dizygotic groups do not differ in depression, whereas their scores are both clearly higher than those of the controls (table 2 ; the monozygotic score not reaching significance due to large SD). This may point to a trend found in Parkinson's disease family studies that depressive illness is encountered more often in relatives of patients with Parkinson's disease than in healthy controls. ${ }^{29}{ }^{30}$ Whether these findings justify the assumption that the higher frequency of depressive mood among the twins reflects dopaminergic compromise lying outside the nigrostriatal system, awaits further confirmation. ${ }^{12}$

Long intervals of discordance between later motor concordant monozygotic twins ${ }^{31}$ make it likely that long term observation of motor discordant twin pairs may change our current estimate of personality and mood concordance. If this is established, personality and mood assessment as signs of non-motor Parkinson's disease may become useful adjuncts in the clinical work up of idiopathic Parkinson's disease in twins. By this, the contribution of genetic factors to Parkinson's disease may be redetermined.

We thank KA Schiffke for help in collecting clinical data; $\mathrm{H}$ Westphal, Institute of Immunology, Christian-Albrechts University Kiel, and G Bein, Institute of Immunology and Transfusion Care, Medical University of Lubeck, assisted in zygosity determination. The work was supported in part by the Deutsche Parkinson Vereinigung and the Schweizerische Parkinsonvereinigung.

1 Ward CD, Duvoisin RC, Ince SE, et al. Parkinson's disease in 65 pairs of twins and in a set of quadruplets. Neurology in 65 pairs of twins

2 Marsden CD. Parkinson's disease in twins. $\mathcal{F}$ Neurol Neurosurg Psychiatry 1987;50:105-6.

3 Marttila RJ, Kaprio J. Koskenvuo MD, et al. Parkinson's disease in a nationwide twin cohort. Neurology 1988;38: $1217-9$

4 Vieregge P. Schiffke KA, Friedrich HJ, et al. Parkinson's disease in twins. Neurology 1992;42:1453-61.

5 Tanner CM, Ottman R, Ellenberg J, et al. Parkinson's disease (PD) concordance in elderly male monozygotic (MZ) and dizygotic (DZ) twins. Neurology 1997;48(suppl 1):A333.

6 Burn DJ, Mark MH, Playford ED, et al. Parkinson's disease in twins studied with ${ }^{18} \mathrm{~F}$-dopa and positron emission tomography. Neurology 1992;42:1894-900.

7 Holthoff VA, Vieregge P, Kessler J, et al. Discordant twins with Parkinson's disease: positron emission tomography with Parkinson's disease: positron emission tomography and early signs of

8 Poewe W, Gerstenbrand F, Ransmayr G, et al. Premorbid personality of Parkinson patients. F Neural Transm Suppl 1983;19:215-24

9 Hubble JP, Venkatesh R. Hassanein RES, et al. Personality and depression in Parkinson's disease. F Nerv Ment Dis 1993;181:657-62.

10 Todes CJ, Lees AJ. The pre-morbid personality of patients with Parkinson's disease. F Neurol Neurosurg Psychiatry 1985;48:97-100.

11 Paulson GW, Dadmehr N. Is there a premorbid personality typical for Parkinson's disease ? Neurology 1991;41(suppl 2):73-6.

12 Javoy-Agid F, Agid Y. Is the mesocortical dopaminergic system involved in Parkinson's disease ? Neurology 1980;30: 1326-31.

13 Menza MA, Golbe LI, Cody RA, et al. Dopaminerelated personality traits in Parkinson's disease. Neurology 1993;43: $505-8$

14 Hornykiewicz O, Kish SJ. Biochemical pathophysiology of Parkinson's disease. Adv Neurol 1986;45:19-34.

15 Ward CD, Duvoisin RC, Ince SE, et al. Parkinson's disease in twins. Adv Neurol 1984;40:341-4.

16 Fahrenberg J, Hampel R, Selg H. Das Freiburger Personlichkeitsinventar (FPI). Revidierte Fassung und teilweise geänderte Fassung FPI-A1. Handanweisung: Göttingen Toronto Zürich: Verlag fur Psychologie Dr CJ Hogrefe, 1984.

17 Zerssen D von, Koeller DM. Paranoid-Depressivitäts-Skala und Depressivitäts-Skala. Manual. Weinheim: Beltz Test, und

18 Zerssen D von. Befindlichkeits-Skala (Bf-S). Weinheim: Beltz Test, 1976

19 Folstein MF, Folstein SE, McHugh PR. Mini-mental state. A practical method for grading the cognitive state of patients for the clinician. F Psychiatr Res 1975;2:189-98.

20 Fahn S, Elton RL, UPDRS Development Committee. Unified Parkinson's disease rating scale. In: Fahn S, Marsden $\mathrm{CD}$, Goldstein M, et al, eds. Recent developments in Parkinson's disease. Vol II: Florham Park, NJ: Macmillan, 1987:153-63.

21 Bouchard TJ, Lykken DT, McGue M, et al. Sources of human psychological differences: the Minnesota study of twins reared apart. Science 1990;250:223-8.

22 Kendler KS, Heath AC, Martin NG, et al. Symptoms of anxiety and symptoms of depression. Same genes, different environments ? Arch Gen Psychiatry 1987;44:451-7.

23 Cloninger CR, Svrakic DM, Przybek TR. A psychobiological model of temperament and character. Arch Gen cal model of temperame

24 Epstein RP, Novick O, Umansky R, et al. Dopamine D4 receptor (D4DR) exon III polymorphism associated with 
the human personality trait of novelty seeking. Nat Genet 1996;12:78-80.

25 Benjamin J Li L, Patterson C, et al. Popula association between the D4 dopamine receptor gene and measures of novelty seeking. Nat Genet 1996;12:81-4.

26 Eatough VM, Kempster PA, Stern GA, et al. Premorbid personality and idiopathic Parkinson's disease. Adv Neurol 1990;53:335-42.

27 Glosser G, Clark C, Freundlich B, et al. A controlled investigation of current and premorbid personality: characteristics of Parkinson's disease patients. Mov Disord 1995;10 201-6.
28 Cassileth BR, Lusk EJ, Strouse TB, et al. Psychosocial status in chronic illness. A comparative analysis of six diagnostic groups. $N$ Engl f Med 1984;311:506-11.

29 Mayeux R, Stern Y, Cote L, et al. Altered serotonin metabolism in depressed patients with Parkinson's disease. Neurology 1984;34:642-6.

30 Santamaria J, Tolosa ES, Valles A, et al. Mental depression in untreated Parkinson's disease of recent onset. Adv Neurol 1986;45:443-6.

31 Zimmerman TR, Bhatt M, Calne DB, et al. Parkinson's disease in monozygotic twins: a follow-up. Neurology 1991; 41(suppl 1):255 